was used to measure the expression of 12 interferon signature genes in the extracted RNA. The study was approved by the University Research Ethics Committee.

Results: $92.4 \%$ of the cohort studied were female. $58.7 \%$ were receiving vitamin D3 supplementation at a mean dose of 1031 IU daily. $27.2 \%$ had vitamin D insufficiency (25-hydroxyvitamin D 21-29ng/ml) and $15.2 \%$ were vitamin D deficient (25-hydroxyvitamin $D<20 \mathrm{ng} / \mathrm{ml}$ ). Mean serum 25 -hydroxyvitamin $D$ was $30.75 \mathrm{ng} / \mathrm{ml}$ (standard deviation $9.53 \mathrm{ng} / \mathrm{ml}$ ). Median SLEDAl-2K was 4 (range $0-12$ ). Serum 25-hydroxyvitamin $D$ had a significant negative correlation with body mass index (BMI) $(R=-0.258, p=0.006)$ but there was no significant negative correlation with SLEDAI-2K or with the expression of the interferon signature genes. The expression of most interferon signatures genes measured (IFI35, OAS1, MX1, IFITM1, STAT2, IFIT3, IFIT1, STAT1, SOCS1) had a significant positive correlation with SLEDAI-2K.

Conclusion: This study did not show a significant relationship between serum vitamin D level and disease activity. In keeping with this, there was no significant negative correlation between serum 25-hydroxyvitamin D and interferon signature gene expression. Further prospective studies and randomised controlled trials are required to study this relationship in greater depth.

References:

[1] Kamen DL, Cooper GS, Bouali H, Shaftman SR, Hollis BW, Gilkeson GS. Vitamin $D$ deficiency in systemic lupus erythematosus. Autoimmun Rev. 2006; 5: 114-7.

[2] Sahebari M, Nabavi N, Salehi M. Correlation between serum 25(OH)D values and lupus disease activity: an original article and a systematic review with meta-analysis focusing on serum VitD confounders. Lupus 2014; 23 : 1164-77.

[3] Arasappan D, Tong W, Mummaneni P, Fang H, Amur S. Meta-analysis of microarray data using a pathway-based approach identifies a 37-gene expression signature for systemic lupus erythematosus in human peripheral blood mononuclear cells. BMC Med. 2011; 9: 65.

Disclosure of Interests: : None declared

DOI: 10.1136/annrheumdis-2020-eular.934

\section{THU0236 EFFICACY AND SAFETY OF NON-MITOGENIC ANTICD3 ANTIBODY ADMINISTRATION IN THE TREATMENT OF LUPUS-PRONE MICE}

M. Morita ${ }^{1}$, S. Masuyama ${ }^{1}$, M. Mizui ${ }^{1}$, Y. Isaka ${ }^{1} .{ }^{1}$ Osaka University, 2-2, Suita, Japan

Background: Systemic lupus erythematosus (SLE) is a multisystem autoimmune disease characterized by the production of autoantibody and systemic tissue damages including glomerulonephritis. Immune responses mediated by autoreactive T-cells, as well as by autoantibody, is involved in the development and progression of end-organ damages ${ }^{1}$. Biologic agents which manipulate T-cell function such as CTLA4-Ig and anti-CD40L have been revisited and tried to treat human SLE, however, both of them failed to demonstrate efficacy.

A mouse specific anti-CD3 $\varepsilon$ mAb, clone $145-2 C 11$ (2C11) is known to be immunosuppressive by down-modulation of TCR and depletion of T-cells ${ }^{2}$. Administration of Fc-deleted $145-2 \mathrm{C} 11 \mathrm{~F}(\mathrm{ab})_{2}$, to lupus-prone mice was reported to reduce lymphadenopathy and prolong survival, but had no significant effect on anti-DNA antibody titer ${ }^{3}$. The mechanisms by which $2 \mathrm{C} 11$ ameliorates lupus are still unclear.

In this study, we used non-mitogenic Fc-modified silent 145-2c11 (2C11S), which disables interaction between target cells and Fc receptor-bearing cells, abolishes antibody directed cytotoxicity, and has longer half-life than $F\left(a b^{\prime}\right)$. 2C11S is expected to exert its effect in safe and stable as compared with functional parent-2C11 (2C11P) antibody.

Objectives: The purpose of our study is to clarify the difference between $2 \mathrm{C} 11 \mathrm{~S}$ and $2 \mathrm{C} 11 \mathrm{P}$ and to examine their therapeutic effects against murine lupus-prone (NZB/W F1) mice.

Methods: $20 \mu \mathrm{g}$ of $2 \mathrm{C} 11 \mathrm{P}$ (absolute antibody), 2C11S (absolute antibody), or isotype control immunoglobulin G1 k (IC)(BioLegend) were administered intraperitoneally to C57BL6 mice. The difference of their action on T-cells were evaluated in a time series from peripheral blood. Plasma cytokine levels were measured within 24 hours after antibody administration.

In NZB/W F1 mice from weeks 10 or 20, 2C11P, 2C11S, and IC were administered (100 $\mu \mathrm{g} /$ week, 4 times, intraperitoneally). Plasma anti-dsDNA antibody titer, spleen and kidney blood cell subpopulation, and histology of renal tissue were evaluated before and/or after treatment.

Results: Duration of reduced TCR expression in 2C11S group was approximately twice as long as that in 2C11P group, and the levels of plasma TNF-a was not increased in $2 \mathrm{C} 11 \mathrm{~S}$ group while significant increase was observed in $2 \mathrm{C} 11 \mathrm{P}$ group (IC; mean $48.3 \pm$ SD 16.7 pg/ml, 2C11S; $57.9 \pm 6.12,2 \mathrm{C} 11 \mathrm{P} ; 168 \pm 50.6$, IC VS 2C11S; $p>0.99$, IC VS 2C11P; $p=0.03$, ANOVA).
In NZB/W F1 mice, the number of follicular helper T (Tfh) cells in spleen significantly decreased in $2 \mathrm{C} 11 \mathrm{~S}$ group (IC; median $9.0^{*} 10^{4}$ [interquartile range $\left.8.5^{\star} 10^{4}\right], 2 \mathrm{C} 11 \mathrm{~S} ; 1.8^{*} 10^{4}\left[1.0^{*} 10^{4}\right], 2 \mathrm{C} 11 \mathrm{P} ; 1.0^{\star} 10^{5}\left[9.4^{*} 10^{4}\right]$, IC VS $2 \mathrm{C} 11 \mathrm{~S}$ $p=0.03$, IC VS 2C11P; $>0.99$, Kruskal-Wallis). The number of germinal center $\mathrm{B}(\mathrm{GCB})$ cells in spleen also decreased in $2 \mathrm{C} 11 \mathrm{~S}$ group (IC; $1.2^{*} 10^{5}\left[1.7^{\star} 10^{5}\right]$ $2 \mathrm{C} 11 \mathrm{~S} ; 9.0^{*} 10^{3}\left[2.3^{*} 10^{4}\right], 2 \mathrm{C} 11 \mathrm{P} ; 8.0^{*} 10^{4}\left[2.3^{*} 10^{5}\right.$ ], IC VS $2 \mathrm{C} 11 \mathrm{~S} ; \mathrm{p}=0.03$, IC VS $2 \mathrm{C} 11 \mathrm{P} ; \mathrm{p}>0.99)$. The number of infiltrating CD4 ${ }^{+} \mathrm{T}$-cells in kidney significantly reduced in $2 \mathrm{C} 11 \mathrm{~S}$ group $\left(\mathrm{IC} ; 3.4^{*} 10^{3}\left[1.0^{*} 10^{4}\right], 2 \mathrm{C} 11 \mathrm{~S} ; 6.4^{*} 10^{2}\left[8.8^{*} 10^{2}\right], 2 \mathrm{C} 11 \mathrm{P}\right.$ $1.2^{*} 10^{3}\left[4.4^{*} 10^{3}\right]$, IC VS 2 C $11 S ; p=0.048$, IC VS 2 C $\left.11 \mathrm{P} ; \mathrm{p}=0.23\right)$. In addition, the rate of increase in anti-dsDNA IgG titers significantly decreased in $2 \mathrm{C} 11 \mathrm{~S}$ group (IC; 2.3 [1.3], 2C11S; 0.9 [1.0], 2C11P; 1.3 [1.4], IC VS 2C11S; $p=0.03$, IC VS $2 \mathrm{C} 11 \mathrm{P} ; \mathrm{p}=0.24)$. Finally, glomerular hypercellularity was markedly alleviated only in $2 \mathrm{C} 11 \mathrm{~S}$ group (IC; $4.4^{*} 10$ [8.4], 2C11S; $3.8^{*} 10$ [1.1], 2C11P; $3.9^{\star} 10$ [8.2], IC VS 2C11S; $p=0.02$, IC VS 2C11P; $p=0.57$ ).

Conclusion: $2 \mathrm{C} 11 \mathrm{~S}$ did not induce cytokine release with maintaining longer effect on TCR down-modulation. 2 C11S reduced autoantibody production by suppressing GCB differentiation, possibly through down-regulation of Tfh cell number. Consequently, 2C11S ameliorated lupus nephritis. On the other hand, 2C11P did not show therapeutic effect.

References:

[1] George C Tsokos. et al. Nat. Rev. Rheum (2016) 12: 716-730.

[2] Kuhn C. et al. Immunotherapy (2016) 8: 889-906.

[3] Henrickson M. et al. Arthritis Rheum (1994) 37: 587-589.

Disclosure of Interests: : None declared

DOI: 10.1136/annrheumdis-2020-eular.1077

\section{THU0237 UNCOVERING DIFFERENCES BETWEEN THE SYSTEMIC LUPUS ERYTHEMATOSUS (SLE) AND HEALTHY IMMUNOMES USING MULTI-PARAMETRIC INTERROGATION}

K. Nay Yaung ${ }^{\star 1,2}$, J. G. Yeo ${ }^{1,3}$, M. Wasser ${ }^{1}$, P. Kumar ${ }^{1}$, S. P. Tang ${ }^{4}$, S. K. Ng$^{4}$ S. L. Poh ${ }^{5}$, T. Arkachaisri ${ }^{1,2,6}, \mathrm{~S}$. Albani ${ }^{2,3,5}$. ${ }^{1}$ Translational Immunology Institute, Singhealth/Duke-NUS Academic Medical Institute, Singapore, Singapore; ${ }^{2}$ Duke-NUS Medical School, Singapore, Singapore; ${ }^{3}$ KK Women's and Children's Hospital, Singapore, Singapore; ${ }^{4}$ Selayang Hospital, Paediatric Rheumatology Unit, Department of Paediatrics, Kuala Lumpur, Malaysia; ${ }^{5}$ Translational Immunology Institute, Singhealth/DukeNUS Academic Medical Institute, Singapore, Singapore; ${ }^{6} \mathrm{KK}$ Women's and Children's Hospital, Rheumatology and Immunology, Singapore, Singapore

Background: Systemic lupus erythematosus (SLE) is a complex, systemic autoimmune disease that interferes with the balance between regulation and immunity, resulting in immune system dysfunction. Disease course is unpredictable due to alternating remissions and flares ${ }^{1}$.

Disease activity and treatment response are measured with composite scores such as the SLE Disease Activity Index (SLEDAI) ${ }^{2}$. However, disease heterogeneity can impede reliable patient assessments. Mechanistic insights into SLE are required for better assessment.

Current studies are mainly descriptive, and a complex disease like SLE is best interrogated with multi-parametric, holistic approaches such as mass cytometry (CyTOF).

Objectives: (1)To characterise immune signatures of newly diagnosed SLE patients and in the process:

a.Study the roles of B and T cells in SLE

b.Gain a holistic understanding of the adaptive immune response

(2)To compare immunological profiles of newly diagnosed SLE patients with agematched healthy controls

We hypothesise that significant differences exist between immunomes of newly diagnosed SLE and healthy subjects.

Methods: Peripheral blood mononuclear cells (PBMCs) of 5 SLE subjects (median age 125 months) were tested with CyTOF. Data was uploaded to an online analytical platform, the Extended Polydimensional Immunome Characterization (EPIC) discovery tool, for comparison with 51 age-matched controls in its database.

Subsequently, normalization and FlowSOM (Flow cytometry analysis by Self-Organising Maps) clustering to 50 nodes were performed with 37 functionally and phenotypically important immune markers. The Mann-Whitney $U$ test identified significantly different cluster frequencies.

Results: Correspondence analysis comparing global differences in cluster frequencies showed segregation of SLE subjects away from healthy controls. Multiple significant differences were identified $(p<0.05)$. Notably, a memory $\mathrm{CD}^{+}{ }^{+} \mathrm{CD} 152^{+} \mathrm{PD} 1^{+} \mathrm{T}$ cell subset $\left(\mathrm{CD} 4^{+} \mathrm{CD} 152^{+} \mathrm{PD} 1^{+} \mathrm{CD} 45 \mathrm{RO}^{+} \mathrm{CD} 25{ }^{-}\right.$FoxP3 $\left.{ }^{-}\right)$ was enriched in SLE (median: $2.17 \%$, interquartile range: 1.66 to $7.74 \%$ of CD45+ PBMCs) versus control (1.34\%, $1.06-1.58 \% ; p=0.00267)$. Expression 